\title{
Examining Healthcare Institutions by Bringing Qualitative Data from Two Eras into Empirical Dialogue
}

Judson G. Everitt

Loyola University Chicago, jeveritt@luc.edu

James M. Johnson

University of Notre Dame

William H. Burr

Stephanie H. Shanower

Follow this and additional works at: https://ecommons.luc.edu/soc_facpubs

Part of the Sociology Commons

Author Manuscript

This is a pre-publication author manuscript of the final, published article.

\section{Recommended Citation}

Everitt, Judson G.; Johnson, James M.; Burr, William H.; and Shanower, Stephanie H.. Examining Healthcare Institutions by Bringing Qualitative Data from Two Eras into Empirical Dialogue. Ethnography, , $\therefore$, 2020. Retrieved from Loyola eCommons, Sociology: Faculty Publications and Other Works, http://dx.doi.org/10.1177/1466138120913062

This Article is brought to you for free and open access by the Faculty Publications and Other Works by Department at Loyola eCommons. It has been accepted for inclusion in Sociology: Faculty Publications and Other Works by an authorized administrator of Loyola eCommons. For more information, please contact ecommons@luc.edu. (c) $(1) \Theta \Theta$

This work is licensed under a Creative Commons Attribution-Noncommercial-No Derivative Works 3.0 License. (c) Sage, 2020. 


\title{
Examining Medical Education by Bringing Qualitative Data from Two Eras into Empirical Dialogue
}

\author{
Judson G. Everitt, James M. Johnson, Will H. Burr, and Stephanie Shanower \\ Loyola University Chicago
}

[UNDER REVIEW: DO NOT CITE OR DISTRIBUTE WITHOUT PERMISSION OF THE AUTHORS.]

Running Head: Medical Education in Two Eras

Keywords: professional socialization; inhabited institutions; medical education; healthcare Word Count: 7,642

*Direct all correspondence to: Judson G. Everitt, Department of Sociology, Loyola University Chicago, 1032 W. Sheridan Rd., Chicago, IL 60660, jeveritt@luc.edu.

**Acknowledgements: We thank Helena Dagadu, Anne Figert, Dana Garbarski, Simone IspaLanda, and Alexandra Vinson for feedback on earlier drafts of this paper. This research was supported by the Faculty Summer Research Stipend Program in the College of Arts and Sciences at Loyola University Chicago. 


\title{
EXAMINING HEALTHCARE INSTITUTIONS BY BRINGING QUALITATIVE DATA FROM TWO ERAS INTO EMPIRICAL DIALOGUE
}

\begin{abstract}
In this paper, we argue there is new insight to be gained by reexamining the classic text, Boys in White, in strategic ways. Specifically, we share excerpts from Boys in White with current medical students and ask for their reactions in qualitative interviews, examining the relevance (or lack thereof) of earlier meanings about professional training for current processes of professional training. We show how we have employed this technique in our current project revisiting Boys in White with current medical students, and discuss preliminary findings that reveal the potential of this technique for documenting evidence of macro-level forces in healthcare institutions using qualitative data on new doctors. We conclude with discussion of alternative approaches through which scholars could make use of this technique in future professional socialization scholarship in ways that shed light on dynamics of institutional persistence and change.
\end{abstract}




\section{INTRODUCTION}

In 1961, Howard Becker, Blanche Geer, Everett Hughes, and Anselm Strauss published their seminal ethnographic study on medical education, entitled Boys in White: Student Culture in Medical School. In it, they revealed that the formal training involved in becoming a physician is not the top-down process of indoctrination and skill-acquisition it was commonly assumed to be. Rather than passive receivers of the new knowledge, technical competencies, and ethical commitments that physicians are required to possess, Becker and his colleagues (1961) instead found that medical students exert a great deal of influence on the medical training process. They develop their own definitions of what is important (and what is not) about their medical training in ways that are, at times, inconsistent with the expectations of the faculty who train them. "Students collectively set the level and direction of their efforts to learn," Becker et al. (1961) write, and they justify their levels and directions of effort on their own terms, "working out in practice... the perspectives from which the students view their day-to-day problems in relation to their long-term goals" (435). By immersing themselves in the daily life of medical education and focusing analytic attention on student culture and perspective, Becker et al. (1961) profoundly shaped how we understand professional socialization as a sociological phenomenon. Moreover, Boys in White (BIW) was foundational to subsequent interactionist studies of professional socialization in the 1970's, 1980's, and 1990's (Cahill 1999; Haas and Shaffir 1977; Kleinman 1983; Light 1980; Sherlock and Morris 1972).

Since its publication, however, the wider sociological research on the professions has shifted attention away from professional socialization and training processes. Scholars operating from a range of theoretical perspectives began placing greater emphasis on professional status 
and authority (Abbott 1988; Freidson 1970; Starr 1982), the role that professions and professional training play in sustaining institutional diffusion and stability (DiMaggio and Powell 1983, 1991; Meyer and Rowan 1977), and the ways in which claims to professional expertise are socially contested and contingent (Brint 1994; MacDonald 1995; Owen-Smith 2011). In many ways, it would seem as though we have turned the page on Boys in White, and its remaining utility as a classic work is limited to serving as a historical artifact of past sociological insight.

In this article, we argue there is new insight to be gained by reexamining Boys in White in strategic ways, and that a particular type of reexamination can serve a long-standing (and recently renewed) methodological interest in capturing direct empirical evidence of macroinstitutional force at play in the micro-interactional processes documented by qualitative data (e.g., Haedicke and Hallett 2016). In particular, we share excerpts from Boys in White with current medical students and ask for their reactions in qualitative interviews, focusing on the relevance (or lack thereof) of earlier meanings about professional training for current processes of professional training. Engaging with classic texts in new research allows scholars to document from the perspective of newcomers what meanings have endured with time, what meanings have been modified with time, and what meanings have been abandoned or displaced with time. It also allows for examination of the institutional pressures which form the taken-for-granted assumptions that undergird the formal structure of organizations and inform newcomers' perspectives. As such, it helps qualitative researchers pin down empirical evidence of macrolevel structure in their micro-level data. First, we discuss our appraisal of the literature on ethnographic approaches to studying institutional dynamics and why the professional socialization literature is well suited to the type of methodological technique we propose. Then, 
we detail how we have employed this technique in our current project revisiting Boys in White with current medical students, and discuss preliminary findings that reveal the potential of this technique in the context of studying healthcare institutions from the perspective of new doctors. We conclude with discussion of alternative approaches that scholars could make use of this technique in future professional socialization scholarship in ways that shed light on dynamics of institutional persistence and change.

\section{THEORY AND LITERATURE}

To trace the history of professional socialization research is to trace some of the key traditions in the discipline. As noted, Becker et al. (1961) represents a foundational piece of work, especially in the symbolic interaction tradition. But Merton, Reader, and Kendall (1957) published The Student Physician just a few years prior, which represents a collection of pieces on medical education rooted in structural functionalism. Because functionalist scholars conceptualize "the professions" in terms of the societal needs they fill via their distinct combinations of expert knowledge and autonomy, they also view professional socialization as a linear process of acquiring expertise, technical skill, and ethical standards (Parsons 1939; Greenwood 1957; Merton, Reader, and Kendall 1957). Becker et al. (1961) reject such conceptualizations. In fact, as Hallett and Gougherty $(2018,30)$ note, Becker et al. (1961) “actually eschew the word 'socialization' because of its association with deterministic, functionalist tradition." And as already noted, Boys in White kicked off a long tradition in professional socialization research informed by symbolic interaction that similarly departs from functionalist origins in sociological understandings of the professions and professional 
socialization (Cahill 1999; Haas and Shaffir 1977, 1982; Kleinman 1983; Light 1980; Sherlock and Morris 1972). This tradition continues to evolve as recent studies on medical education are firmly rooted in symbolic interaction (Jenkins 2018; Vinson 2019) and represent part of a larger literature in the sociology of medical education (Brosnan and Turner 2009).

This body of work, and symbolic interaction more broadly, is not without its criticisms. One of the most common (and arguably most overstated) is that it is too inattentive to social structure (however, see Maines 1977 and Stryker 1980 for clear exceptions). Indeed, Boys in White exemplifies this shortcoming. There is little analytic attention to the ways medical students' student cultures are shaped by the organizational conditions at the University of Kansas Medical School or the institutional arrangements of the medical profession or healthcare more broadly. A so far small group of scholars, however, is working to breathe new life into the sociological study of professional socialization, in part, by explicitly addressing this common critique of prior studies informed by symbolic interaction (Everitt 2013, 2018; Gougherty 2016; Hallett and Gougherty 2018). These scholars and their work are rooted firmly in the symbolic interactionist traditions exemplified by Becker et al. (1961), but also expand upon them by bringing them into analytic conversation with neo-institutional theory.

Part of a growing scholarship known as inhabited institutionalism (Hallett and Ventresca 2006; Hallett 2010), these recent studies of professional socialization employ ethnography to examine the local interactions and meaning making that drive the transition processes of professional socialization while also directly examining how those processes are enabled and constrained by formal structures in the institutional environment (Everitt 2018; Gougherty 2016). Inhabited institutionalism, and its use in the study of professional socialization to date, overcomes this "a-structural" problem of symbolic interaction by analyzing the complex ways 
that rationalized cultural ideals - or what neo-institutionalists would call "institutional myths" (Meyer and Rowan 1977) - are brought to bear on newcomers' meaning making about becoming a member of the profession. Everitt (2018), for instance, examines how prospective teachers both modify and reproduce rationalized meanings about accountability and compulsory education that structure public education, developing a "culture of ambivalence" that emerges out of their interpretive responses to the competing pressures that structure the work of teaching. From this standpoint, new teachers inhabit their professional socialization by creatively reconstructing the meaning of the rules of educational institutions and making them relevant to the daily dilemmas they confront on their own terms (Everitt 2018). In this sense, institutional arrangements such as accountability and compulsory education are not seen as "neutral" components of new teachers" environment, as prior work in symbolic interaction theorizes (Blumer 1960); they are forceful guidelines for action with their own histories. At the same time, teacher candidates do not conform unreflectively with institutional rules that structure their training, making them the "pool of interchangeable individuals who... possess a similarity of orientation," as prior work in neo-institutionalism theorizes (DiMaggio and Powell 1983, 152); they actively modify and reproduce the meanings of institutional myths.

An inhabited institutional examination of professional socialization overcomes the shortcomings of these theoretical traditions by engaging their respective strengths with each other in complementary ways. Indeed, inhabited institutionalism has informed a number of empirical studies on the way that people and institutions mutually constitute each other across a range of organizational settings (Aurini 2012; Binder 2007; Cobb 2017; Dorado 2013; Everitt 2012; Haedicke 2012; Hallett 2010; Nunn 2014; Reyes 2015). Despite the breadth of inhabited institutionalism across different types of organizations, this scholarship has yet to fully explore 
how time and history shape the ways that institutions are inhabited. Elaborating the role of time and history is consistent with inhabited institutionalism's origins. Hallett and Ventresca (2006), as well as Hallett (2010), identify empirical cases of key organizational change (new management in both cases) and examine how people in these settings make sense of this change. These authors show the importance of "then vs. now" comparison, but from the perspective of the people and organizations who experienced the change itself. We extend this idea to the comparison of different people's meaning making about a similar process in different moments of an institution's history. To be sure, healthcare has undergone significant institutional change over the second half of the $20^{\text {th }}$ century (Scott et al. 2000), making it an institutional environment particularly well-suited for "then vs. now" comparison.

Not only is professional socialization structured by the institutional arrangements within which it unfolds, but socialization across the life course has its own structural features. Corsaro (2018) theorizes that childhood is a "structural form" that is temporary and transitional for children going through it, but it is also a stable feature of society that structures people's interactions and defines social roles. Initial professional socialization comprised of formal training programs is a similar structural form, one that continues to inform subsequent socializing experiences that span people's careers (Everitt and Tefft 2019). Initial training is a temporary process and status for the individuals as they go through it, but it is a stable feature of society and its institutions. Such durability of professional socialization as a structural form lends itself to useful comparison across historical windows of time. Most research on socialization processes examines people's interactions and meaning making at key points within, or as they transition through, key structural forms of the life course (Adler, Kless, and Adler 1992; Corsaro 1994; Corsaro and Molinari 2005; Eder 1995; Fine 1987; Thorne and Luria 1986). To our 
knowledge, there are no studies that compare the experiences and meaning making of people transitioning through the same structural form of professional socialization in two different historical windows of time. Our methodological approach enables such comparison.

\section{DATA AND METHODS}

We first began revisiting the empirical content of Boys in White itself, and reanalyzed it using more contemporary theoretical and methodological tools. In addition, we have 31 in-depth qualitative interviews with current medical students that document their perspectives on their training, the challenges endemic to physicians working in current healthcare institutions, and how they define their professional responsibilities. Our analytic strategy is to engage the two data sources with each other, both in drawing direct comparisons between perspectives of medical students past and present, as well as inviting current medical students to respond to past medical students' perspectives.

The data present in Boys in White, after transcribed, produces approximately 80 singlespaced pages of textual data. Among the total number of interviews, we purposefully sampled to include students in all four years of medical school. Students in years 1 and 2 primarily complete academic training, and students in years 3 and 4 complete clinical rotations. We included more students in years 3 and 4 who can discuss the range of their experiences throughout both phases of medical school (see Table 1). Such sampling is important for the research design, as it allows for documenting medical students' perspectives about the rigors of their coursework as well as their initial training experiences that take them into the prospective work environments of healthcare institutions. Among our 31 respondents, 20 are women. This represents a distinct 
demographic difference from the respondents in Boys in White who were overwhelmingly men (hence the title), and also reflects a clear change in the overall gender composition of medicine over time. The interviews are semi-structured, and focus on medical students' experiences in their own terms. In this way, the methodology is consistent with established protocols in qualitative sociology that emphasize the need to document and engage first with respondents' meanings, perspectives, and experiences rather than testing for confirmation of existing theoretical concepts (Emerson, Fretz, and Shaw 2011; Tracy 2010; Weiss 1994). Interview questions address students' challenges during coursework, dilemmas they confronted in clinical experiences, how they think prospectively about transitioning into the status of physician, and finally, how they view key excerpts from the medical students studied in Boys in White. The medical school from which we interviewed students is an allopathic medical school affiliated with a private university in the Midwest granting doctor of medicine (MD) degrees. The medical school and its teaching hospital have six programs that are nationally ranked, and the hospital ranks among the top five in its state.

From the beginning we were interested in medical students' perspectives on competing pressures within the institutional environment for which they are training to enter, an interest sparked by Everitt's (2018) analysis of how teachers-in-training make sense of competing institutional pressures. In addition, though, we wanted to incorporate an historical element to the analysis. We were originally inspired by prior scholarship that shows the promise and utility in revisiting classic texts and reinterpreting their contents to develop new theoretical insights (Hallett and Ventresca 2006). But we also wanted to incorporate new data collection with contemporary medical students so that we could compare the experiences of medical students now with those of medical students in a prior generation as documented by Becker et al. (1961). 
At first, this comparison between these two data sources was the extent of our methodological goals. But as we began crafting the interview protocol, while examining the Boys in White data as well, it occurred to us: why not let the medical students we were interviewing respond directly to the content of Boys in White? Especially since a central goal of the analysis is to compare the meanings and perspectives about training and the work of medicine among medical students in two different eras, we saw great potential insights in asking medical students two read excerpts from the data presented in Boys in White and explain to us in their terms what was relevant to their experience, what was not, and why. In other words, we thought there could be much to learn from novices to medicine by asking them how their experiences are both similar and different to those of novices in an earlier era.

As we worked through the decision-making process to include this type of exercise in our research design, we grappled with potential concerns. Primarily, we feared the potential for our efforts to simply produce a methodological artifact. In other words, we were asking our medical students to engage with, and respond to, text and ideas that they would not have otherwise engaged with or responded to had we not provided them the text and asked them to respond to examples of its contents. This concern, though important to reflect upon, is assuaged for us by two factors. First, there is precedent for the effective use of artifacts in qualitative interviews to solicit and document meanings that participants have already formed or are in the process of forming. Nunn (2014), for instance, uses transcripts of hypothetical high school students in interviews with high school students. She was able to get high school students to elaborate in greater detail how they define what she calls "success identities" by applying their definitions of success to hypothetical others. As such, the hypothetical transcripts helped Nunn (2014) clarify the meanings students had already formed. We believe our approach accomplishes something 
similar. Second, one could argue that an interview protocol itself produces methodological artifacts, so the use of excerpts or vignettes is no different than using any number of essential tools for data collection that directly solicit responses from participants (i.e., an interview questionnaire or survey).

\section{BRINGING BOYS IN WHITE DATA TO INTERVIEWS WITH CURRENT MEDICAL STUDENTS}

Two key patterns of preliminary findings have emerged in the early stages of our analysis, and we present some examples of each pattern here. In both cases, we see current medical students engaging in the same kinds of active meaning making that Becker at al. (1961) document so vividly, but we also see current students responding to, and making sense, of different institutional dynamics that have changed since the Boys in White fieldwork. For the preliminary analysis we discuss in this paper, we focus on key institutional changes in higher education that are brought to bear on medical schools and medical students. Specifically, we examine interrelated curricular, technological, and economic changes in higher education, and how current medical students actively make sense of them via meaning-making processes similar to the student cultures found in Boys in White.

What to Study: From "What Faculty Want" to "I Never Went to Lectures"

One of the key empirical findings from Becker et al. (1961) was the way in which medical students actively determined for themselves "the level and direction of effort" through 
ongoing interaction in their own student cultures. From these processes, medical students in Boys in White made a transition in how they attempted to study all of the material that comprised the content of their coursework in their early years in medical school. Initially, first-year students attempted to learn all of the material (what Becker and colleagues call the "initial perspective"), but quickly became overwhelmed with the sheer volume of material (the "provisional perspective"). They then began trying to anticipate what their faculty would likely test them on (the "final perspective"), and adjust their studying accordingly even though faculty largely expected them to "learn it all," so to speak. An excerpt from Boys in White that we shared with our current medical students captures this:

Now this second one, this is the one on collateral circulation. I just happened to hit that by luck. The night before the exam I was going through the book and I saw this thing about the subscapular artery and a couple of pages on I saw there was a whole network of little vessels in there and I got interested and I started to study it. So really that was just luck, but that's all we can do I guess. First we study the things that we think are important and then we study the things that we think they [faculty] think are important. Only it's hard to get them all in. There isn't time.

[Becker et al. 1961,

Current medical students engage in similar strategizing, often collectively, but they focus on different goals and rely on different resources as they set the level and direction of their effort to study enormous amounts of material. They similarly go through a transition in how they make 
sense of these dynamics. In the first year, they take a similar approach as first-year students in Boys in White: they focus on coursework and try to "learn it all." This approach is facilitated somewhat by a type of block scheduling at this medical school that attempts to make the amount of material manageable in the first year. But once the second year begins, they make a similar realization that there is simply too much; as one student described it, "you can only know so much, and you try to focus on what we say is high yield." They respond with somewhat different strategies and meaning making than Boys in White students. They begin doing two things in the second year: they stop going to class, and they rely on video technology and web-based resources for content. Irene, a second-year student from our study discusses this and her reasons for it:

Irene: So, I was a big class goer my first year, not so much now. I think that's because now second year, they know how much material there is. And the commercial side of medical school knows how much material there is, especially what the boards test people on, so there's a lot of really great resources that synthesize a lot of that high yield information. Modes that are a little more easily digested than just hearing it in lecture. I use Pathoma which is a pretty widely used pathology resource that has a workbook as well as course videos that break down pathology processes from like all of the organ systems that correlate really well with the boards and our actual in-class lectures. I always go through at least the handouts — so the PowerPoints or the pdfs for the lectures - as well as trying to get to watching all of the lectures before the exam, as well.

[Interview with Irene, $2^{\text {nd }}$-year Med Student] 
We see students actively making sense of their training in ways similar to Boys in White students: they begin by going to class, but quickly realize there is too much and adjust course. But rather than attempt to handicap what their faculty will define as important, they turn attention to the expectations for "the Boards,", or Step 1 of the United States Medical Licensing Exam (USMLE) that awaits them after their second year. Indeed, passing the USMLE Step 1is consequential for current medical students' degree progress: if they do not pass, they will not complete medical school. Moreover, their scores also strongly influence the type and caliber of residency program for which they will be eligible. Because Step 1 is so critical to subsequent phases of their training, they prioritize prep for Step 1 over exceling in their actual medical school classes. Most students merely seek passing grades in their coursework while devoting most of their studying to exam prep, especially in the second year. Like their Boys in White predecessors, they modify their shared perspective about studying during years one and two, but in response to different institutional arrangements that call for different strategies.

As Irene notes, current medical students respond to dynamics of the institutional environment that have changed since the Boys in White era of medical education. Step 1 of the USMLE is a computer-based exam, and there has been a proliferation of online sources for test prep that are closely aligned with Step 1 content (often described as "high yield" by students). Students consistently report using these sources along with video recordings of their course lectures also posted online ("Pathoma," a program out of the University of Chicago, is a very popular example, along with "Sketchy Medical"). They then study on their own time, often speeding up the video through parts they deem less important and focusing on the content they believe is important. Another student further describes this approach to studying: 
Like, I always listened to my lectures, I'd listen to the lecture to see what the exam would be about, but to actually learn the material, I listened to Pathoma... I love Pathoma and those lectures are very organized and I think they're pretty high yield, so yeah I would listen to those. And I would listen to them as a supplement to my lectures, but I never took my lectures seriously. [joint laughter]... I never went to lectures." [Interview with Kerry, $4^{\text {th }}$-Year Med Student]

A second-year medical student also describes how ubiquitous these types of practices are among medical students, as well as how Step 1 of the USMLE is such a driving force motivating these shared practices:

I honestly don't think I can name a medical student who doesn't use some sort of outside resource during their second year just because... I think there's just the pressure of you don't have to just do well in class now, but like we have Boards at the end of the year and that is quite literally the most important test of our lives. [Interview with Garrett, $2^{\text {nd }}$-Year Med Student]

Our medical students engage in active meaning making about the appropriate level and direction of effort much the same way that Boys in White medical students did; the micro-level meaning-making processes via interaction are very similar. But the institutional environment has changed with time, and we see medical students adjusting the content of their meaning making about their training in ways that are creative responses to these contemporary dynamics. 
It's not about the Money: From Using "All Your Medical Knowledge" to "The Rise in Student Debt"

Another finding from Becker et al. (1961) includes the ways that medical students downplay the role that money and compensation play in driving their meaning making about the profession. Below is an excerpt that offers an example of what this meaning making looks like, and we also shared this excerpt with our current medical students:

Yesterday some of the guys were talking about their ideas of a successful physician. Have you got any ideas about that?" Phil said, "That is a good question." Dick said, "I haven't thought about that. I don't think it's the money though. I don't think that is the only thing." Phil said, "I don't think money has anything to do with it." Dick said, "I think it's more a matter of whether you can use all your knowledge, your medical knowledge, in your practice.” Phil said, "Well, I think being in the position to help people is important too, but it's hard for us to say about this now."

[Becker et al. 1961]

For Boys in White medical students, money does not "have anything to do with it," when it comes to their motivation for pursuing medicine or how they expect to practice medicine. As Dick says, "I think it's more a matter of whether you can use all your knowledge, your medical knowledge in your practice." 
When we shared this with current medical students, an interesting combination of similarities and differences in meaning making about the role of money emerges. An excerpt from our interview with Henry, and third-year student, captures this preliminary pattern:

Interviewer: Do you think that- I mean, does anything there resonate with your experience and what you've seen today?

Henry: Yes and no. Personally I think I have, um, this similar attitude. You know it's not about the money. It's about what you can do with your skills. Um... Nowadays though with tuition increasing every single year by 2 to 4 percent. Uh, with the compensation for physicians decreasing over time. Um, with the rise in student debt that everyone has, a medical student or no medical student, it's very hard to stick with those values that brought you into medicine in the first place. I need to pay off my debt. How am I going to do that? Make more money. What specialties make more money? And I feel like over time, um, money has become more of an issue for students and, uh, some students might not go into the specialty they like the most or they feel like they belong to. But they go into something else because the compensation is better. And I think that leads some unhappy doctors.

Interviewer: Is that something that, um, you and your classmates or people that are a year or two ahead of you. I mean, will you talk about student debt and how much this is all costing and, you know, "I really love to do primary care, but that's 
not really an option for me." I mean, what, what are those, what does that look like?

Henry: Uh, I think it's on pretty much most people's minds, but it's a little bit taboo to talk about. Because we need to be all for the patient. We need to do, you know, what we're good at and we're not here for the money. We're here to help people. But I think it's definitely a concern for a lot of people how it's supposed to be is that you do what you want to do. You feel like you do what you feel like you belong to. And the money is just a benefit. But uh, people are coming out of school with hundreds of thousands of dollars in debt and, um, they're worried about that debt, you know. So I think that money comes up in conversation but usually only with like good friends or people that you trust.

[Interview with Henry, $3^{\text {rd }}$-year Med Student]

Henry similarly downplays the role of money in his motivation for pursuing and practicing medicine. However, he cannot ignore one of the most dramatic changes to the institutional environment in higher education broadly and medical education specifically: cost, and the concomitant rise in student loan debt. As Henry notes, this institutional change is concretely shaping medical students' decision-making about specialty areas through which they will practice medicine. Due to debt, they seek specialties that will help them "make more money." Such a perspective is similar to Schleef's (2006) finding that lawyers seek out "jobs of least resistance" that are high-paying and interfere less in one's personal life. Medical students define this as a new source of pressure to opt for specialties rather than primary care, and this 
relationship between medical student meaning making and the institutional environment serves to aggravate existing shortages of primary care physicians.

Other students echo Henry's sentiment and its effects on specialty decisions:

I agree with that [Boys in White excerpt], that the money doesn't have everything to do with it. But I think the money is important for med students because we're in so much debt. So that's one thing. Because I know I've had experiences with med students where people like my friends that originally really wanted to do something like family medicine or something else. But then later on they're like, "Oh my God, I'm going to have so many debts. I think I should do anesthesiology." So I think that money doesn't have to do with everything, but it does matter a little bit. [Interview with Tiffany, 3rd-Year Med Student]

For current medical students, money or income is not their primary motivation for pursuing medicine, but it does begin informing their decision-making while they are in medical school as the prospect of repaying growing debt becomes more of an impending reality. While most medical students downplay the role money plays in their meaning making about their careers, they do expect a certain high standard of living and the looming debt interferes with that expectation.

I mean, the amount of debt is insane that people have to take on to be a medical student, and then you really don't always get compensated as much as you want to. And especially for going back to like primary care, it's really hard to be 
compensated as much as I think some doctors deserve, you know, in the field of like family practice [or] pediatrics and whatnot. I know a lot of people have factored that in their decision-making, and that certain specialties are going to earn them more, and they'll be debt free faster. For me personally, I was able to get a lot of help from my parents, which was really nice and I'm very grateful for that. So I will come out with less debt then is average, which is wonderful. So I try not to factor it in too much, but there is something to be said about: you work for nine years doing something, you do want a fair compensation, especially when you can be up to like five hundred thousand dollars with debt. [Interview with Diana, $4^{\text {th }}$-Year Med Student]

It is important to note the similarities in how current medical students downplay the importance of money, to the point that they believe the issue of student debt is "a little bit taboo to talk about" and they lament the ways that debt is relevant. Just as Boys in White medical students emphasized "using all of our medical knowledge" and being "in a position to help people," Henry emphasizes his commitment to "be all for the patient," and that "we need to do what we're good at and we're not here for the money." Likewise, Tiffany agrees with her Boys in White predecessors that "money doesn't have everything to do with it," but the debt is an unavoidable way in which it is relevant that prior generations of doctors did not confront. Current students cannot ignore the constraint of student debt, and it is a key institutional condition that they inhabit as they engage in similar micro-level meaning making that Becker et al. (1961) previously documented. 


\section{DISCUSSION AND CONCLUSION}

Our project is in process, yet we feel that this approach will offer further insights into particular tensions between permanence and change in healthcare institutions, and help advance inhabited institutionalism as well. We also speculate that different versions of this approach could be widely applicable for future research, and could serve as a useful tool in a broader reinvigoration of professional socialization research in sociology. Our methodology and findings advance inhabited institutionalism by revealing how time and history inform the ways people inhabit institutions. We find evidence of both persistence and change in micro-level processes of meaning-making and group culture, as well as macro-level institutional structures. The current medical students in our study share many similarities in their student cultures as the medical students in Boys in White: they collectively determine their own level and direction effort in how to study through their student cultures, and this does not align fully with the expectations of their faculty. In this sense, micro-dynamics key to medical education have endured with time.

But the content of student meaning making about their training has changed in response to specific institutional changes in the environment. Certainly, the demographics of medical education have changed since the 1950 's, and this is reflected in our interview data primarily in the number of women in our sample. While these changes no doubt drive changes in student culture over time, the patterns we report here are meaning-making processes that students explicitly link to institutional changes rather than demographic ones. The influence of highstakes testing has increased in medical education through policies of the Federation of State Medical Boards and the National Board of Medical Examiners. Current medical students are more concerned with passing these tests than excelling in their classes, whereas Boys in White 
medical students were fixated on their classes and the content on which their faculty were likely to test them. Likewise, the cost of higher education broadly has soared in the decades between now and Boys in White (Houle 2014), introducing a constraint of student loan debt for current medical students that was simply absent for Boys in White students. Indeed, inhabited institutionalism emphasizes that "institutions and individuals mutually constitute each other" (Everitt 2018: 12), but we show how historical context also informs and shapes the ways people inhabit similar institutions.

Our specific exercise in using a classic sociological text in new data collection depends upon the existence of such a classic text on the process of professional socialization. Not all areas of inquiry into professional socialization will likely have such a seminal work as part of the prior literature on the topic. But other types of older texts and documents exist that capture meanings and assumptions about professional training processes and programs in earlier time periods. We argue that systematically using codifying texts - such as formal curriculum, evaluation rubrics, textbooks and course syllabi, program accreditation documents, etc. - from particular programs' histories in new data collection with contemporary trainees is a promising way of examining tensions between institutional permanence and change in a wide range of professional training programs that span different professions, organizations, and institutions.

Longitudinal, comparative ethnography is certainly a powerful methodology for examining institutional dynamics in life course transitions, as Corsaro (2018) demonstrates, but such methods are challenging given the amount of time required to spend in the field. Analyzing the content of formal documents relevant to an organizational environment has strong precedent in the tradition of institutional ethnography (Smith 2005). Subjecting the content of formal documents allows researchers to analyze explicit statements of the often taken-for-granted 
assumptions that undergird the formal structure of organizations, and also helps qualitative researchers pin down empirical evidence of macro-level structure in their micro-level data. While Everitt (2018) includes examination of programmatic documents in his ethnography of teachers' professional socialization, he only includes formal documents that are current to the teacher candidates in the study and the program that they were completing at the time. Using formal documents from an earlier point in the program's history, sharing them with current informants, and asking for their reactions allows researchers to document the relevance (or lack thereof) of earlier structures on professional entry for current processes of professional entry. It allows researchers to document from the perspective of newcomers what meanings have endured with time, what meanings have been modified with time, and what meanings have been abandoned or displaced with time. Since most training programs keep archives of formal documents over time, such exercises should be feasible in most cases across different types of programs and professions.

Learning to become a member of a profession involves learning the rules of the institutional environment for that profession. Going back to Boys in White, we know that this process is neither rote nor linear, and involves active interpretation on the part of newcomers. Indeed, recent studies show that professional socialization is a key process through which people inhabit institutional arrangements (Everitt 2018; Everitt and Tefft 2019; Hallett and Gougherty 2018). Moreover, while institutional environments are durable over time, elements of them change with some frequency. Prior scholarship on professional socialization, despite its rich tradition and important insights, has not been able to shed much light on processes of permanence and change in the institutions that structure it. We hope that the technique of using older texts and formal documents in future research on professional socialization may offer 
scholars a useful tool in reviving professional socialization research by adding to our understanding of the complex ways that people and institutions mutually constitute other.

\section{REFERENCES:}

Abbott, Andrew. 1988. The System of Professions: An Essay on the Division of Expert Labor. Chicago: University of Chicago Press.

Adler, Patricia A., Steven J. Kless, and Peter Adler. 1992. "Socialization to Gender Roles: Popularity among Elementary School Boys and Girls.” Sociology of Education 65: 169187.

Aurini, Janice D. 2012. "Patterns of Tight and Loose Coupling in a Competitive Marketplace: The Case of Learning Center Franchises." Sociology of Education 85: 373-87.

Becker, Howard S. and Blanche Geer. 1958, "The Fate of Idealism in Medical School.” American Sociological Review 23:50-56.

Becker, Howard S., Blanche Geer, Everett C. Hughes, and Anselm L. Strauss. 1961. Boys in White: Student Culture in Medical School. Chicago: University of Chicago Press.

Binder, Amy J. 2007. 'For Love and Money: Organizations' Creative Responses to Multiple Environmental Logics." Theory and Society 36: 547-71.

Blumer, Herbert. 1960. Industrialization as an Agent of Social Change. New York: Aldine de Gruyter.

Blumer, Herbert. 1969. Symbolic Interactionism: Perspective and Method. Edgewood Cliffs, NJ: Prentice Hall Inc.

Brint, Steven. 1994. In an Age of Experts: The Changing Role of Professionals in Politics and Public Life. Princeton: Princeton University Press. 
Brosnan, Caragh and Bryan S. Turner (eds.). 2009. Handbook of the Sociology of Medical Education. New York: Routledge.

Cahill, Spencer. 1999. "Emotional Capital and Professional Socialization: The Case of Mortuary Science Students (and Me)." Social Psychology Quarterly 62: 101-16.

Corsaro, William A. 2018. The Sociology of Childhood ( $5^{\text {th }}$ edition). Los Angeles: SAGE.

Corsaro, William A. and Luisa Molinari. 2005. I Compagni: Understanding Children's Transition from Preschool to Elementary School. New York: Teachers College Press.

DiMaggio, Paul and Walter W. Powell. 1983. "The Iron Cage Revisited: Institutional Isomorphism and Collective Rationality in Organizational Fields." American Sociological Review 48: 147-60.

DiMaggio, Paul and Walter W. Powell. 1991. "Introduction." Pp. 1-38 in Walter W. Powell and Paul DiMaggio (eds.) The New Institutionalism in Organizational Analysis. Chicago: University of Chicago Press.

Dorado, Silvia. 2013. "Small Groups as Context for Institutional Entrepreneurship: An Exploration of the Emergence of Commercial Microfinance in Bolivia." Organization Studies 34: 533-57.

Eder, Donna, with Catherine C. Evans, and Stephen Parker. 1995. School Talk: Gender and Adolescent Culture. New Brunswick, NJ: Rutgers University Press.

Emerson, Robert M., Rachel I. Fretz, and Linda L. Shaw. 2011. Writing Ethnographic Fieldnotes ( $2^{\text {nd }}$ edition). Chicago: University of Chicago Press.

Everitt, Judson G. 2012. "Teacher Careers and Inhabited Institutions: Sense-Making and Arsenals of Teaching Practice in Educational Institutions." Symbolic Interaction 35: 20320. 
Everitt, Judson G. 2018. Lesson Plans: The Institutional Demands of Becoming a Teacher. New Brunswick, NJ: Rutgers University Press.

Everitt, Judson G. and Taylor Tefft. 2019. “Professional Socialization as Embedded Elaborations: Experience, Institutions, and Professional Culture throughout Teacher Careers.” Symbolic Interaction (DOI: 10.1002/symb.409).

Fine, Gary Alan. 1987. With the Boys: Little League Baseball and Preadolescent Culture. Chicago: University of Chicago Press.

Freidson, Eliot. 1970. Professional Dominance: The Social Structure of Medical Care. Atherton Press.

Gougherty, Matthew T. 2016. “Assembling Professionalism: Education in a Masters of Public Affairs Program.” Doctoral Dissertation. Indiana University. ProQuest Dissertations Publishing.

Greenwood, Ernest. 1957. “Attributes of a Profession.” Social Work 2: 45-55.

Haas, Jack and William Shaffir. 1977. "The Professionalization of Medical Students: Developing Competence and a Cloak of Competence." Symbolic Interaction 1: 71-80.

Haedicke, Michael A. 2012. “'Keeping Our Mission, Changing Our System': Translation and Organizational Change in Natural Foods Co-ops.” The Sociological Quarterly 53: 44-67.

Haedicke, Michael A. and Tim Hallett. 2016. "How to Look Two Ways at Once: Research Strategies for an Inhabited Institutionalism.” Pp. 99-111 in The Handbook of Qualitative Organizational Research: Innovative Pathways and Methods, edited by Kimberly D. Elsbach and Roderick M. Kramer. Routledge.

Hallett, Tim. 2010. “The Myth Incarnate: Recoupling Processes, Turmoil, and Inhabited Institutions in an Urban Elementary School.” American Sociological Review 75: 52-74. 
Hallett, Tim and Marc Ventresca. 2006. "Inhabited Institutions: Social Interactions and Organizational Forms in Gouldner's Patterns of Industrial Bureaucracy.” Theory and Society 35: 213-36.

Hallett, Tim and Matt Gougherty. 2018. "Professional Education in the University Context: Towards an Inhabited Institutional View of Socialization.” Pp. 144-80 in Education in a New Society: Renewing the Sociology of Education, edited by Jal Mehta and Scott Davies. Chicago: University of Chicago Press.

Houle, Jason N. 2014. 'Disparities in Debt: Parents' Socioeconomic Resources and Young Adult Student Loan Debt." Sociology of Education 87:53-69.

Jenkins, Tania M. 2018. "Dual Autonomies, Divergent Approaches: How Stratification in Medical Education Shapes Approaches to Patient Care." Journal of Health and Social Behavior 59: 268-82.

Kleinman, Sherryl. 1983. "Collective Matters as Individual Concerns: Peer Culture among Graduate Students." Journal of Contemporary Ethnography 12: 203-25.

Light, Donald. 1980. Becoming Psychiatrists: The Professional Transformation of Self. New York: Norton.

MacDonald, Keith M. 1995. The Sociology of Professions. London: Sage Publications.

Maines, David R. 1977. “Social Organization and Social Structure in Symbolic Interactionist Thought." Annual Review of Sociology 3: 235-59.

Merton, Robert K., George G. Reader, and Patricia L. Kendall (eds.). 1957. The Student Physician: Introductory Studies in the Sociology of Medical Education. Cambridge: Harvard University Press. 
Meyer, John W. and Brian Rowan. 1977. "Institutionalized Organizations: Formal Structure as Myth and Ceremony." American Journal of Sociology 83: 340-63.

Nunn, Lisa M. 2014. Defining Student Success: The Role of School and Culture. New Brunswick, NJ: Rutgers University Press.

Owen-Smith, Jason. 2011. "The Institutionalization of Expertise in University Licensing." Theory and Society 40: 63-94.

Parsons, Talcott. 1939. “The Professions and Social Structure.” Social Forces 17: 457-67.

Reyes, Daisy Verduzco. 2015. “Inhabiting Latino Politics: How Colleges Shape Students' Political Styles.” Sociology of Education 88: 302-19.

Scott, W. Richard, Martin Ruef, Peter J. Mendel, and Carol A. Caronna. 2000. Institutional Change in Healthcare Organizations: From Professional Dominance to Managed Care. Chicago: University of Chicago Press.

Sherlock, Basil J. and Richard T. Morris. 1972. Becoming a Dentist. Springfield, IL: Charles C. Thomas Publisher.

Smith, Dorothy E. 2005. Institutional Ethnography: A Sociology for People. Lanham, MD: Altamira Press.

Smith, Allen and Sherryl Kleinman. 1989. “Managing Emotions in Medical School.” Social Psychology Quarterly 52: 56-69.

Starr, Paul. 1982. The Social Transformation of American Medicine. New York: Basic Books. Stryker, Sheldon. 1980. Symbolic Interactionism: A Social Structural Version. Caldwell, NJ: The Blackburn Press.

Thorne Barrie and Zella Luria. 1986. “Sexuality and Gender in Children's Daily Worlds.” Social Problems 33: 176-90. 
Tracy, Sarah J. 2010. “Qualitative Quality: Eight ‘Big-Tent’ Criteria for Excellent Qualitative Research.” Qualitative Inquiry 16:837-51.

Vinson, Alexandra H. 2019. "Short White Coats: Knowledge, Identity, and Status Negotiations of First-Year Medical Students." Symbolic Interaction 42: 395-411.

Weiss, Robert S. 1994. Learning from Strangers: The Art of Method of Qualitative Interview Studies. New York: The Free Press. 